\title{
Congenital malformations and maternal occupation: a registry based case-control study
}

\author{
Fabrizio Bianchi, Domenico Cianciulli, Anna Pierini, Adele Seniori Costantini
}

\begin{abstract}
Objectives-To investigate the relations between congenital malformations and maternal occupation during pregnancy with a registry based case-control study. Methods-Analysis was performed on data derived from the Florence Eurocat registry surveillance programme. The study included cases with isolated conditions, including chromosomal anomalies ( $n=1351)$, cases with multiple anomalies registered during the $1980-91$ period $(n=$ 440), and babies with no congenital malformations recognised at birth who were born from 1982 to 1989 and selected as controls $(n=3223)$. 11 categories were defined, 10 including cases with isolated malformations and one for cases with multiple congenital anomalies. Four categories of maternal occupation were selected for the study. Odds ratio (OR) values were adjusted for maternal origin, maternal and paternal education, number of previous live births, illness during pregnancy, and maternal age when the group of chromosomal anomalies was analysed.
\end{abstract}

Results-A notable and significant association between oral clefts and mothers involved in leather and shoe manufacturing was found (adjusted OR 3.9; $99 \%$ confidence interval (99\% CI) 1.5 to 9.8$)$ and the risk consistently increased when considering cases with isolated cleft palate separately (OR 5.4; $95 \%$ CI 1.8 to 13.4 ). Moreover, a significant risk was identified for the association between multiple anomalies and textile dye workers (adjusted OR 1.9; 99\% CI 1.0 to 3.8).

Conclusions-This study indicates a notable, significant relation between maternal occupation as a pelt or leather worker and orofacial clefts in offspring. This finding is in agreement with the suggested inheritance models. The dilution effect due to studying large and heterogeneous groups of workers and occupations limits the value of the study; but it provides a good example of the use of a large database to search for teratogenic risk with the aid of malformation registries.

(Occup Environ Med 1997;54:223-228)

Keywords: congenital malformations; maternal occupation; case-control; orofacial cleft
The association between maternal occupation and congenital malformations in offspring has been repeatedly described by registry based case-control studies, and other important results on occupational exposure have been obtained from epidemiological studies.

From case-control investigations, major anomalies of the central nervous system have been reported in association with the maternal occupation "sales worker" during the first trimester and oral clefts have been associated with health service carers, clerical workers, and the repair services industry. ${ }^{1}$

Among women involved in healthcare work, a relation between maternal exposure to anaesthetic gas and various malformations has been described several times with postal questionnaires: however, the only study performed in Sweden with medical records did not suggest increases in risk. ${ }^{2} \mathrm{~A}$ significant association was found among cases with birth defects whose mothers had been exposed, as nurses, to cytostatic drugs, but no specific pattern of defects was identified. ${ }^{3}$ For exposure to anaesthetic gases, evidence of increased risk of congenital malformations was considered inconclusive. ${ }^{4}$

In epidemiological studies focused on hairdressers, associations were found with menstrual disorders and spontaneous abortions, as well as other inconsistent results probably due to methodological problems. ${ }^{5}$

For leather workers a relevant reproductive risk has been reported of perinatal mortality due to all causes (and particularly to congenital malformations ${ }^{6}$ ), fetal mortality (but not for congenital malformations ${ }^{7}$ ), and subfecundity. ${ }^{8}$

Another study, conducted in Norway, found an odds ratio (OR) of 0.77 for congenital malformations and occupation in textile and leather industries. ${ }^{9}$

Evidence on the risk of oral cleft in offspring of mothers exposed to solvents during pregnancy has sometimes been described. ${ }^{10-12}$ Recently, a significant association (OR 1.9) for orofacial cleft and agricultural work during pregnancy has been identified by a case-control study based on the Finnish register of congenital malformations, but exposure to solvents did not explain the association found. ${ }^{13}$

The aim of the present registry based casecontrol study was to explore associations among selected groups of congenital anomalies and four groups of maternal occupations during pregnancy. 


\section{Materials and methods}

Since 1979 the Province of Florence (Italy) has been part of the Eurocat concerted action project. ${ }^{14}$ Between 1982 and 1989 a case-control surveillance was carried out with the primary aim of preparing a database to describe and investigate relations between congenital malformations and hypothetical risk factors. The present study includes 1146 births and induced abortions fcr isolated conditions, 205 with chromosomal anomalies and 440 with multiple anomalies, registered in eight maternity units during the $1980-91$ period, as well as 3223 controls, normal at birth, registered in the same hospitals from 1982 to 1989 . Cases were selected among all births and induced abortions with congenital malformations collected according to the Eurocat guidelines. ${ }^{15}$ One out of 20 normal live or stillbirths, resident in the study area, was included in the control group. In effect, every normal birth occurring after 19 consecutive births was selected as a control in each maternity unit (the subsequent normal birth was selected as a control when the 20th had malformations); this selection was performed basically for organisational reasons at the maternity units. The sampling fraction of $1 / 20$ was chosen to build up a control group of at least double the size of the group of cases, assuming 2.5 per 100 to be the prevalence of congenital malformations among the births. The control group did not include abortions due to causes other than congenital malformations.

In each maternity unit, mothers of cases and controls were interviewed (not blindly) by the same neonatologist, involved in the Eurocat registry. A standardised questionnaire, based on the Eurocat form, ${ }^{15}$ was used to collect information about both cases and controls.

Specific questions on the maternal occupation and branch of activity during pregnancy were asked. An unstructured section was provided for the specific job title and possible risk agents, even if a reduced level of completeness and reliability was expected. Neither previous working periods nor duration of exposure during the present pregnancy were investigated by the questionnaire. However, the interviewers were instructed to ask specific questions about any "moonlighting" jobs.
Coding of maternal occupation was performed by the central staff of the Florence Eurocat registry according to the three digit ISTAT classification of occupations. ${ }^{16}$

To select groups of occupations for analysis, three inclusion or exclusion criteria were used: (a) occupation in which at least 10 women were exposed when all malformations were considered; $(b)$ an existing interest on the basis of the scientific literature; $(c)$ exclusion of groups with generically defined occupationsfor example, mechanical worker.

With the above criteria, four groups of occupations were selected: health service carers (ISTAT code $1 \cdot 4 \mathrm{x}$ ), hairdressers (ISTAT code $9 \cdot 4 \mathrm{x}$ ), textile dye workers (ISTAT code $5 \cdot 3 x$ ), and leather workers (ISTAT code $5 \cdot 5 x$ ). (See table 6 for some occupational titles of interest compared with the ISCO-88 code. $)^{17}$

Coding of congenital malformations was carried out with the British Paediatric Association classification of diseases and grouping by the Eurocat schedule. ${ }^{18} 19$

In the present study, 10 classes of isolated congenital malformations and one class of multiple conditions (two or more major congenital malformations) were considered (table 1). Some groups of isolated anomalies were excluded due to the small numbers, such as eye $(n=13)$, ear $(n=15)$, respiratory $(n=$ 8 ), metabolic ( $n=10$ ), other major congenital malformations $(\mathrm{n}=18)$, and a miscellaneous group of other minor isolated or associated anomalies $(n=41)$.

Malformation sequences-such as Potter's sequence-were considered to be a single anomaly, whereas anomalies of known environmental origin-for example, fetal alcohol syndrome, toxoplasmosis-or monogenic syndromes were excluded: this left 73/1969 cases $(3 \cdot 7 \%)$, a percentage comparable with many other registries.

An assessment of the diagnosis reported at the local level is routinely performed by medical geneticists at the central level, taking into account the reported environmental exposure. Nevertheless, the possibility that some unrecognised syndromes were included among the multiple anomalies cannot be ruled out.

Crude ORs $(95 \%$ confidence intervals $(95 \%$

Table 1 Groups of anomalies considered in the study and number of cases available for analysis

\begin{tabular}{|c|c|c|c|}
\hline $\begin{array}{l}\text { Group of } \\
\text { anomalies }\end{array}$ & $B P A C D$ code* & Total cases & $\begin{array}{l}\text { Induced abortions } \\
n(\%)\end{array}$ \\
\hline Nervous system & $\begin{array}{l}7400-7402,7410,7419-7425,7428,7429,3440-3449, \\
2250-2259,3519,2375-2379,3526,2370-2372\end{array}$ & 106 & $41(38 \cdot 7)$ \\
\hline $\begin{array}{l}\text { Cardiovascular } \\
\text { Oral cleft } \\
\text { Digestive }\end{array}$ & $\begin{array}{l}7450-7469,4253,7852,7470-7476,7478,7479 \\
7490,7491,7492 \\
7503,75121,75122-75124,7504,7505,7507-7519\end{array}$ & $\begin{array}{r}296 \\
79\end{array}$ & $1(0 \cdot 3)$ \\
\hline & $2110-2119$ & 90 & - \\
\hline $\begin{array}{l}\text { External genital } \\
\text { Internal urogenital }\end{array}$ & $\begin{array}{l}7524-7528,7786 \\
7520-7523,7529,7530-7539,2190-2229,2231-2233 \\
2330,2238-2239\end{array}$ & $\begin{array}{r}123 \\
83\end{array}$ & $5(6.0)$ \\
\hline $\begin{array}{l}\text { Limbs } \\
\text { Muscoloskeletal }\end{array}$ & $\begin{array}{l}7550-7556,7558,7559,7543-7547 \\
7444,7500-7502,5240,5249,7445,7448,7449,7480, \\
7481,7540-7542,7560,7506,7566,7548,7561-7569 \\
5509,5530-5532,5538,5539,2380,5209\end{array}$ & 237 & $1(0 \cdot 4)$ \\
\hline $\begin{array}{l}\text { Teguments } \\
\text { Chromosomal }\end{array}$ & $\begin{array}{l}7570-7575,7578,7579,6851,2140,2169,2280-2281 \\
7580-7589\end{array}$ & $\begin{array}{r}65 \\
205\end{array}$ & $60(29 \cdot 3)$ \\
\hline Multiple anomalies & two or more anomalies listed above & 440 & $28(6.4)$ \\
\hline
\end{tabular}


Table 2 Distribution of sociodemographic variables for cases and controls

\begin{tabular}{|c|c|c|c|}
\hline \multirow[b]{2}{*}{ Variable } & \multirow{2}{*}{$\begin{array}{l}\text { Cases } \\
(n=1791) \\
n(\%)\end{array}$} & \multicolumn{2}{|l|}{ Controls } \\
\hline & & $\begin{array}{l}(n=3223) \\
n(\%)\end{array}$ & OR $(95 \% C I)$ \\
\hline \multicolumn{4}{|l|}{ Maternal age ${ }^{\star}$ : } \\
\hline $\begin{array}{l}<35 \\
\geqslant 35 \\
\text { Unknown }\end{array}$ & $\begin{array}{c}1337(88 \cdot 6) \\
178(11 \cdot 4) \\
31\end{array}$ & $\begin{array}{r}2877(89 \cdot 9) \\
327(10 \cdot 2) \\
19\end{array}$ & $\begin{array}{l}1.0 \mathrm{r} \\
1.1(0.9 \text { to } 1.4)\end{array}$ \\
\hline \multicolumn{4}{|c|}{ Origin of the mother: } \\
\hline Central Italy & $1228(72 \cdot 2)$ & $2316(74 \cdot 3)$ & $1.0 \mathrm{r}$ \\
\hline North & $43(2 \cdot 5)$ & $84(2 \cdot 7)$ & $1.0(0.7$ to 1.4$)$ \\
\hline South & $330(19 \cdot 4)$ & $594(19 \cdot 1)$ & $1.1(0.9$ to 1.2$)$ \\
\hline Foreign & $99(5 \cdot 8)$ & $124(4 \cdot 0)$ & $1 \cdot 5(1 \cdot 1$ to $2 \cdot 0)$ \\
\hline \multirow{2}{*}{\multicolumn{4}{|c|}{$\begin{array}{l}\text { Maternal employment at the } \\
\text { beginning of pregnancy: }\end{array}$}} \\
\hline & & & \\
\hline $\begin{array}{l}\text { None } \\
\text { Yes }\end{array}$ & $545(30 \cdot 8)$ & $1086(33 \cdot 8)$ & $1.0 \mathrm{r}$ \\
\hline $\begin{array}{l}\text { Yes } \\
\text { Unknown }\end{array}$ & $\begin{array}{r}1224(69 \cdot 2) \\
22\end{array}$ & $2125(66 \cdot 2)$ & $1.2(1.0$ to 1.3$)$ \\
\hline \multicolumn{4}{|c|}{ Education of the mother: } \\
\hline None & $18(1 \cdot 0)$ & $22(0 \cdot 7)$ & $1.6(0.8$ to 3.2$)$ \\
\hline Primary & $1007(57 \cdot 5)$ & $1697(53 \cdot 1)$ & $1 \cdot 2(1 \cdot 1$ to $1 \cdot 3)$ \\
\hline High school & $561(32 \cdot 0)$ & $1116(35.0)$ & $1.0 \mathrm{r}$ \\
\hline University & $165(9 \cdot 4)$ & $364(11 \cdot 4)$ & $0.9(0.7$ to 1.1$)$ \\
\hline \multirow{2}{*}{\multicolumn{4}{|c|}{ Education of the father: }} \\
\hline & & & \\
\hline None & $19(1 \cdot 1)$ & $17(0 \cdot 5)$ & $2 \cdot 2(1 \cdot 1$ to $4 \cdot 5)$ \\
\hline Primary & $1022(58 \cdot 6)$ & $1775(55.9)$ & $1 \cdot 1(1.0$ to 1.3$)$ \\
\hline High school & $505(28.9)$ & $977(30 \cdot 8)$ & $1.0 \mathrm{r}$ \\
\hline University & $198(11 \cdot 4)$ & $408(12 \cdot 8)$ & $0.9(0.8$ to 1.2$)$ \\
\hline Unknown & 47 & 46 & \\
\hline
\end{tabular}

${ }^{\star}$ Excluding 205 cases with chromosomal anomalies.

$r=$ reference value.

Table 3 Distribution of variables of obstetric history for cases and controls

\begin{tabular}{|c|c|c|c|}
\hline \multirow[b]{2}{*}{ Variable } & \multirow{2}{*}{$\begin{array}{l}\text { Cases } \\
(n=1791) \\
n(\%)\end{array}$} & \multicolumn{2}{|l|}{ Controls } \\
\hline & & $\begin{array}{l}(n=3223) \\
n(\%)\end{array}$ & OR $(95 \% C I)$ \\
\hline \multicolumn{4}{|c|}{ Previous live births: } \\
\hline 0 & $1058(60 \cdot 2)$ & $1817(57 \cdot 2)$ & $1.0 \mathrm{r}$ \\
\hline 1 & $548(31 \cdot 2)$ & $1109(34 \cdot 9)$ & $0.9(0.8$ to 1.0$)$ \\
\hline $\begin{array}{l}>1 \\
\text { Unknown }\end{array}$ & $\begin{array}{c}151(8 \cdot 6) \\
34\end{array}$ & $\begin{array}{l}249(7 \cdot 8) \\
48\end{array}$ & $1.0(0.8$ to 1.3$)$ \\
\hline \multicolumn{4}{|c|}{ Previous stillbirths: } \\
\hline 0 & $1731(98 \cdot 4)$ & $3146(99 \cdot 0)$ & $1.0 \mathrm{r}$ \\
\hline 1 & $25(1 \cdot 4)$ & $30(0.9)$ & $1.5(0.9$ to 2.7$)$ \\
\hline$>1$ & $3(0 \cdot 2)$ & $3(0 \cdot 1)$ & $1.8(0.3$ to 11.2$)$ \\
\hline Unknown & 32 & 44 & \\
\hline \multicolumn{4}{|c|}{ Previous spontaneous abortions: } \\
\hline 0 & $1445(82 \cdot 3)$ & $2623(82 \cdot 6)$ & $1.0 \mathrm{r}$ \\
\hline 1 & $242(13 \cdot 8)$ & $443(13.9)$ & $1.0(0.8$ to 1.2$)$ \\
\hline $\begin{array}{l}>1 \\
\text { Unknown }\end{array}$ & $69(3.9)$ & $111(3 \cdot 5)$ & $1.1(0.8$ to 1.6$)$ \\
\hline \multicolumn{4}{|c|}{ Previous therapeutic abortions: } \\
\hline $\begin{array}{l}0 \\
1\end{array}$ & $1650(94 \cdot 2)$ & $2936(92 \cdot 5)$ & $1.0 \mathrm{r}$ \\
\hline$>_{1}^{1}$ & $91(5 \cdot 2)$ & $197(6 \cdot 2)$ & $0.8(0.6$ to 1.1$)$ \\
\hline $\begin{array}{l}>1 \\
\text { Unknown }\end{array}$ & $\begin{array}{l}15(0 \cdot 8) \\
35\end{array}$ & $\begin{array}{l}41(1 \cdot 3) \\
49\end{array}$ & $0.7(0.3$ to $1 \cdot 2)$ \\
\hline
\end{tabular}

Table 4 Distribution of lifestyle variables during pregnancy for cases and controls

\begin{tabular}{|c|c|c|c|}
\hline \multirow[b]{2}{*}{ Variable } & \multirow{2}{*}{$\begin{array}{l}\text { Cases } \\
(n=1791) \\
n(\%)\end{array}$} & \multicolumn{2}{|l|}{ Controls } \\
\hline & & $\begin{array}{l}(n=3223) \\
n(\%)\end{array}$ & OR $(95 \% C I)$ \\
\hline \multicolumn{4}{|c|}{ Mother's drug use: } \\
\hline Yes & $958(55 \cdot 0)$ & $1763(55 \cdot 7)$ & $1.0(0.9$ to 1.1$)$ \\
\hline No & $783(45 \cdot 0)$ & $1401(44 \cdot 3)$ & $1.0 \mathrm{r}$ \\
\hline Unknown & 50 & 59 & \\
\hline \multicolumn{4}{|c|}{ Mother's smoking status: } \\
\hline Yes & $437(25 \cdot 0)$ & $725(22.9)$ & $1.1(1.0$ to 1.3$)$ \\
\hline $\begin{array}{l}\text { No } \\
\text { Unknown }\end{array}$ & $1309(75 \cdot 0)$ & $2444(77 \cdot 1)$ & $1.0 \mathrm{r}$ \\
\hline \multicolumn{4}{|c|}{ Mother's alcohol use: } \\
\hline Yes & $739(42 \cdot 6)$ & $1606(50 \cdot 8)$ & $0.7(0.6$ to 0.8$)$ \\
\hline $\begin{array}{l}\text { No } \\
\text { Unknown }\end{array}$ & $994(57 \cdot 4)$ & $1557(49 \cdot 2)$ & $1.0 \mathrm{r}$ \\
\hline \multirow{2}{*}{\multicolumn{4}{|c|}{ Infection or illness during pregnancy: }} \\
\hline & & & \\
\hline No & $1311(76 \cdot 0)$ & $2567(81.6)$ & $1.0 \mathrm{r}$ \\
\hline Unknown & 66 & 76 & \\
\hline
\end{tabular}

$\mathbf{r}=$ reference value.
CIs)) were calculated for case-control associations with the sociodemographic variables (table 2), the obstetric history variables (table 3 ), and the lifestyle variables (table 4), with EPI Info software. ${ }^{20}$

To study the associations among 11 groups of malformations and the four occupations selected (table 5), adjusted ORs were calculated for those variables that accounted for significant differences between cases and controls and that were potentially associated with maternal occupation.

When the chromosomal anomalies group was analysed, the adjustment variables were: maternal place of birth (foreign or in Italy), particularly as an indirect indicator of the socioeconomic status; maternal and paternal education (primary, other levels); previous live births $(0,1,>1)$; illness during pregnancy (no, yes); and maternal age ( $\geqslant 35,<35)$. Maternal alcohol consumption was not considered for the adjustment owing to its weak reliability. None of the other potential confounding variables reached significance when tested against employment or unemployment.

To minimise the possibility of producing significant results by chance, adjusted ORs with $99 \%$ CIs were calculated by means of unconditional logistic regression, with EGRET software. ${ }^{21}$ When subgroups of leather workers and oral clefts were compared, crude ORs with $95 \%$ CIs were reported (table 6 ), owing to the few cases.

The number of cases gathered in the subgroups of malformations, with 0.05 first type error and 0.20 second type error (power $80 \%$ ), will allow detection of ORs from 1.5 when the frequency of cases and the percentages of exposures are high-for example, association of multiple congenital anomalies with health service carers-to $3 \cdot 2$ for the associations with fewer subjects-for example, teguments anomalies with hairdressers.

\section{Results}

During the 1982-9 period, 3223 births without congenital malformations were collected as controls out of 70214 births resident in the study area, compared with 3511 expected on the basis of the $1 / 20$ sampling fraction. Underreporting was partly expected as the selection of controls was from the total births minus the malformed babies, and some organisational difficulties were thought likely to be responsible for other missing data. The actual underestimation (about 8\%) was uniformly distributed among the participating hospitals.

All 1969 malformed babies and induced abortions after prenatal diagnosis registered between 1980 and 1991 out of the 106074 total births (prevalence 18.6 per 1000 births) made up the group of cases, as there seemed to be no contraindication to limiting case selection to the same period as that considered for controls.

No significant changes in the pattern of women's employment were found either for cases during the 1980-91 period or for controls over the 1982-9 period. Table 1 shows 
Table 5 Maternal occupation during pregnancy for cases and controls, by groups of anomalies

\begin{tabular}{|c|c|c|c|c|c|c|c|c|c|}
\hline \multirow{3}{*}{ Group of anomalies } & \multirow{2}{*}{$\begin{array}{l}\text { Total } \\
\text { (Controls } \\
=3223 \text { ) } \\
\text { Cases }\end{array}$} & \multicolumn{2}{|c|}{ Health service } & \multicolumn{2}{|c|}{ Hairdresser } & \multicolumn{2}{|c|}{ Textile dye work } & \multicolumn{2}{|c|}{ Pelt or leather work } \\
\hline & & \multicolumn{2}{|c|}{ (Controls $=141)$} & \multicolumn{2}{|c|}{ (Controls $=52$ ) } & \multicolumn{2}{|c|}{ (Controls $=84)$} & \multicolumn{2}{|c|}{$($ Controls $=120)$} \\
\hline & & & & & & & & & \\
\hline Nervous system & 106 & 1 & $0.2(0.0$ to 2.5$)$ & 2 & $1 \cdot 2(0 \cdot 2$ to $8 \cdot 1)$ & 2 & $0.8(0.1$ to 5.0$)$ & 3 & $0.9(0.2$ to 4.0$)$ \\
\hline Cardiovascular & 296 & 8 & $0.6(0.2$ to 1.5$)$ & 7 & $1.6(0.5$ to 4.6$)$ & 7 & $1.0(0.3$ to 2.8$)$ & 11 & $1.1(0.5$ to 2.6$)$ \\
\hline Oral cleft & 79 & 1 & $0.3(0.0$ to 3.6$)$ & 3 & $2.2(0.4$ to 10.7$)$ & 4 & $1.9(0.5$ to 7.4$)$ & 10 & $3.9(1.5$ to 9.8$)$ \\
\hline Digestive & 90 & 5 & $1.2(0.3$ to 3.9$)$ & - & - & 3 & $1.5(0.3$ to 6.9$)$ & 6 & $2.3(0.7$ to $7 \cdot 1)$ \\
\hline External genital & 123 & 9 & $1.8(0.7$ to 4.4$)$ & 1 & $0.4(0.0$ to 6.0$)$ & 3 & $0.9(0.2$ to 4.0$)$ & 4 & $0.8(0.2$ to 3.1$)$ \\
\hline Internal urogenital & 83 & 4 & $1.0(0.3$ to 3.8$)$ & - & - & 2 & $1.0(0.1$ to 6.4$)$ & 1 & $0.4(0.0$ to 4.9$)$ \\
\hline Limbs & 237 & 7 & $0.6(0.2$ to 1.7$)$ & 8 & $2 \cdot 2(0.8$ to $6 \cdot 1)$ & 8 & $1.4(0.5$ to 3.8$)$ & 12 & $1.4(0.6$ to 3.3$)$ \\
\hline Musculoskeletal & 67 & 1 & $0.3(0.0$ to 4.3$)$ & - & - & 2 & $1.2(0.2$ to 8.1$)$ & 4 & $1.9(0.5$ to 7.4$)$ \\
\hline Teguments & 65 & 4 & $1.4(0.4$ to 5.6$)$ & 1 & $0.9(0.1$ to 12.9$)$ & 3 & $1.8(0.4$ to 8.6$)$ & 4 & $1.8(0.4$ to 6.9$)$ \\
\hline Total isolated & 1146 & 40 & $0.8(0.5$ to 1.2$)$ & 22 & $1.2(0.6$ to 2.4$)$ & 34 & $1.2(0.7$ to $2 \cdot 0)$ & 55 & $1.4(0.9$ to 2.1$)$ \\
\hline $\begin{array}{l}\text { Chromosomal } \dagger \\
\text { Multiple }\end{array}$ & $\begin{array}{l}205 \\
440\end{array}$ & $\begin{array}{r}9 \\
11\end{array}$ & $\begin{array}{l}0.9(0.3 \text { to } 2.6) \\
0.5(0.2 \text { to } 1.2)\end{array}$ & $\begin{array}{r}3 \\
11\end{array}$ & $\begin{array}{l}1.0(0.2 \text { to } 5.4) \\
1.7(0.7 \text { to } 4.0)\end{array}$ & $\begin{array}{r}6 \\
20\end{array}$ & $\begin{array}{l}0.9(0.3 \text { to } 3.3) \\
1.9(1.0 \text { to } 3.7)\end{array}$ & $\begin{array}{r}6 \\
24\end{array}$ & $\begin{array}{l}0.7(0.2 \text { to } 2.2) \\
1.7(0.9 \text { to } 3.1)\end{array}$ \\
\hline
\end{tabular}

* Odds ratio adjusted for maternal country of birth, maternal and paternal education, previous live births, illness in pregnancy.

†Odds ratio adjusted for maternal country of birth, maternal and paternal education, previous live births, illness in pregnancy, and maternal age.

Table 6 Maternal occupation during pregnancy in pelt or leather industry for controls and cases with isolated oral cleft, cleft palate, and cleft lip with or without palate

\begin{tabular}{|c|c|c|c|c|c|c|c|}
\hline \multirow[b]{2}{*}{ Occupation } & \multirow{2}{*}{$\begin{array}{l}\text { Controls } \\
(n=3223) \\
n\end{array}$} & \multicolumn{2}{|c|}{ Total oral cleft } & \multicolumn{2}{|c|}{ Cleft palate } & \multicolumn{2}{|c|}{ Cleft lip \pm palate } \\
\hline & & \multicolumn{2}{|c|}{ Cases $(n=79)$} & $\begin{array}{l}C a \\
n\end{array}$ & $\begin{array}{l}=35) \\
\text { OR }(95 \% C I)\end{array}$ & $\begin{array}{l}C a \\
n\end{array}$ & 44) $O R(95 \% C I)$ \\
\hline $\begin{array}{l}\text { Tanner or leather dyer } \\
\text { (ISTAT code }=5 \cdot 51 ; \text { ISCO-88 }=7441 \text { ) }\end{array}$ & 11 & 1 & $3.7(0.1$ to 26.3$)$ & 1 & $8 \cdot 6(0 \cdot 2$ to $62 \cdot 1)$ & - & - \\
\hline $\begin{array}{l}\text { Shoemaker and related workers } \\
\text { (ISTAT code }=5 \cdot 52 ; \text { ISCO-88 }=7442 \text { ) }\end{array}$ & 28 & 2 & $3.0(0.3$ to $12 \cdot 1)$ & 1 & $3.4(0.1$ to 21.6$)$ & 1 & $2 \cdot 6(0 \cdot 1$ to $16 \cdot 8)$ \\
\hline $\begin{array}{l}\text { Leather goods makers } \\
\text { (ISTAT code }=5 \cdot 53 ; \text { ISCO- } 88=7442)\end{array}$ & 81 & 7 & $3.8(1.4$ to 8.5$)$ & 4 & $5.0(1.2$ to 14.6$)$ & 3 & $2.8(0.5$ to 9.2$)$ \\
\hline $\begin{array}{l}\text { Total pelt or leather workers } \\
(\text { ISTAT code }=5 \cdot 5 ; \text { ISCO- } 88=744)\end{array}$ & 120 & 10 & $3.7(1.7$ to 7.6$)$ & 6 & $5.4(1.8$ to 13.4$)$ & 4 & $2.6(0.7$ to 7.3$)$ \\
\hline
\end{tabular}

the frequency of cases included in the study, by group of anomalies and status upon registration. Induced abortions made up $6.4 \%$ of multiple and $8.4 \%$ of isolated anomalies, $38.7 \%$ of anomalies of the nervous system, and $29.3 \%$ of chromosomal anomalies, and for the other groups a small or zero percentage was found.

Table 2 shows the sociodemographic characteristics of cases and controls. No significant difference was found for maternal age between cases and controls when chromosomal anomalies, with an established association with maternal age, were excluded. Within this group, however, the number of subjects with maternal age $\geqslant 35$ years was significantly higher among cases than controls, as expected. No significant differences were found for the mother's place of birth among cases and controls for the three Italian areas (north, centre including Florence, and south including islands), whereas foreign origin was significantly more frequent among cases. More mothers were employed during pregnancy among the cases, although this difference was not significant. Among cases, maternal education to primary level and paternal absence of schooling were significantly different from controls, both parents of cases tended to have had no schooling or schooling to only primary level, but there were no other differences in schooling from the reference high school level.

Table 3 shows data about history of previous pregnancies. There was a slight but significant excess of one previous live birth among the controls, but no difference between still births or abortions, spontaneous or therapeutic. Nevertheless, the high ORs for one or more than one previous still birth are notewor- thy (OR 1.5 and 1.8 , respectively).

Table 4 shows variables related to lifestyle. The proportion of mothers reporting either drug misuse or tobacco smoking during pregnancy was similar in cases and controls; alcohol consumption was significantly more frequent in controls (probably underreported because of a more frequent recall bias among the cases). Among the cases a significant excess of infections or illnesses during pregnancy was found.

There was a low rate of non-response for all the categorical variables already described. Maximum values for missing data were $1.9 \%$ among cases and $1.5 \%$ among controls when simple questions were investigated (maternal age and obstetric history variables), whereas for the other variables "not known" answers were reported in $<5.0 \%$ among cases and $<3.3 \%$ among controls.

Table 5 shows the ORs ( $99 \% \mathrm{CIs)}$ corresponding to the association between four groups of maternal occupations and the different groups of congenital malformations. A significant relation between maternal occupation in the pelt or leather industry and overall oral cleft in offspring was identified (crude OR $3 \cdot 7$; $99 \%$ CI 1.5 to 9.3 ; adjusted OR 3.9 ; $99 \%$ CI 1.5 to $9 \cdot 8$ ).

A risk of multiple abnormalities was also associated with textile dye workers (crude OR $1.8 ; 99 \%$ CI 0.9 to 3.4 ; adjusted OR $1.9 ; 99 \%$ CI 1.0 to $3 \cdot 8$ ).

Table 6 shows the analysis for oral cleft, isolated cleft palate, and cleft lip with or without cleft palate, by subclassification of the pelt or leather group into tanners and leather dyers (ISTAT code $=5.51$ ), shoemakers and related workers (ISTAT code $=5 \cdot 52$ ), and 
leather goods makers (ISTAT code $=5.53$ ).

Of the 35 cases with isolated cleft palate, six had mothers who were leather or shoe workers, resulting in an increased crude OR (OR $5 \cdot 4 ; 95 \%$ CI $1.8-13 \cdot 4$ ), whereas for cleft lip with or without cleft palate the association between the four mothers employed in the leather trade among 44 total cases was weaker and not significant (OR $2 \cdot 6 ; 95 \%$ CI $0 \cdot 7-7 \cdot 3$ ).

\section{Discussion}

There are limitations inherent to this study.

(1) The power of the study is weak, despite its overall size, as only a few cases were present for analysis of selected occupations with groups of anomalies, and so identification of small excesses of risk was reduced.

(2) As the interviews were not performed blindly, a related bias cannot be ruled out, although the interviewers were specifically trained to investigate moonlighting occupations.

(3) Organisational difficulties may have caused underreporting from controls, mainly due to some discontinuities in coverage by the neonatologist involved in the registration, but this is unlikely to have caused notable anomalies.

(4) Unmatched selection of controls was performed, although it was decided to include only those controls resident in the study area. On checking for heterogeneity in notification among eight hospitals, we found only one, in the centre of Florence, which reported anomalies (particularly congenital heart defects) more than the others.

(5) Maternal occupations were grouped loosely to achieve adequately sized groups. Thus, consideration of the type of declared occupation rather than the type of exposure may have resulted in a limitation of the recall bias.

There were also advantages in our study.

(1) The inclusion of induced abortions due to a prenatal diagnosis of congenital malformations represents an important feature.

(2) No significant differences in ratios of isolated or multiple anomalies existed among hospitals, probably because of a good standardisation between neonatologists.

(3) The frequency of "unknown" answers obtained for the maternal and paternal variables was low. Some of the few that there were could be due to difficulties in submitting the questionnaires, especially for the cases.

(4) The answers to questionnaire studies tend not to be specific possibly because of the structure of the study.

In general, as substantial differences exist in risk factors associated with employment related to pregnancy, with working women generally having more favourable demographic and behavioural characteristics and less favourable reproductive histories, it is essential when a case-control study is performed, to be aware of the most important potential confounding factors that distinguish employed women from unemployed women. ${ }^{22}$

Some methodological studies have shown that even although reporting bias for maternal occupation cannot be ruled out, concerns about recall bias are likely to be overrated in studies of birth defects, and that the use of normal controls is acceptable unless evidence of substantial recall bias exists. ${ }^{23}$ The results obtained for the sociodemographic, obstetric, and lifestyle factors included in the study showed considerable agreement with other data reported, particularly in recent publications. ${ }^{12} \mathrm{~A}$ higher alcohol consumption during pregnancy was reported among the controls than among the cases. However, the uncertainty about the timing and amount of consumption was considered to be an indication for the exclusion of these data from the adjustment variables. Other sociodemographic and obstetric history variables are routinely collected for the birth medical record, and both are easier to obtain by questionnaire, so they are more likely to be reliable.

Maternal age was significantly higher among the cases only if chromosomal anomalies were pooled with the other groups considered. Maternal foreign origin was in excess among the cases, but the frequency was small.

This study indicates a significant relation between maternal occupation as a pelt or leather worker and orofacial clefts in offspring. The OR is higher, as well as more significant, when considering cases with isolated cleft palate separately (table 6). It is noteworthy that none of the 10 newborn cases had a family history of congenital malformations (including third degree relatives) whereas among the 69 cases in whom mothers were otherwise employed we found a family history in three cases of cleft lip and palate (two cases with the same defect in a third degree relative of both mother and father and one case with a cleft palate in the sister).

Table 6 shows significant ORs for makers of leather goods for both total oral clefts and cleft palate only. Moreover, a non-significant risk of cleft palate was also associated with tanners or leather dyers and shoemakers, and the sample size was small. These findings are in agreement with the inheritance models recently suggested for cleft palate and cleft lip..$^{24-27}$

A specific relation between employment as a leather worker and birth defects has not yet been proved, but the few observational studies performed in this field should be taken into account. In our experience, in the manufacturing cycle of pelt or leather factories, such as tanneries and shoe and leather goods factories, employees can be reasonably assumed to be exposed to organic solvents. ${ }^{28}{ }^{29}$ Although no assumptions can be made about intensity, degree, and duration of this exposure, it is relevant to report that aliphatic hydrocarbons are often used, as well as chlorinated hydrocarbons and aromatic solvents other than benzene. ${ }^{29}$

No association between defects of the nervous system and maternal occupation as a leather worker was found in our analysis, although such a relation has been previously described. ${ }^{30}$ On the other hand, there is a small amount of evidence that structural or func- 
tional defects of the central nervous system are due to parental exposure, even though the few studies and the wide range of different compounds considered as organic solvents limit the conclusions. ${ }^{31}$ When the nervous system and chromosomal anomalies groups are analysed, the high percentages of induced abortions among the cases must be taken into account.

There was no evidence of an association between maternal occupation and urinary tract defects. This is in agreement with the findings of Cordier et al,,$^{12}$ although a definite excess due to exposure to aromatic solvents has been described. ${ }^{32}$

The relation between multiple anomalies and textile dye workers approached significance, increasing the interest in this group of defects. ${ }^{33}$ Identification of new multiple congenital anomalies combined with exposure evaluation is considered to be a powerful research technique for discovering human teratogens and mutagens. ${ }^{34}$

Among the 20 cases with multiple malformations occurring in textile dyeworkers some associations seem to be noteworthy: hydrocephaly and cleft palate; hydrocephaly, and cleft lip and palate; cleft palate, absence of diaphragm, and low set ears; cleft palate, common mesentery, and talipes equinovarus; spina bifida and congenital heart diseases; in another three cases (congenital heart diseases, absence of auditory canal, and polydactily; ventricular septal defect, oesophageal atresia, common mesentery, and absence of diaphragm; cleft palate, pterygium colli, polydactily, and other oesophageal anomaly) a supplementary investigation on diagnosis and family history is in progress to check for recognised conditions. Among the other cases no particular pattern of associations was found.

The dilution effect due to studying large and heterogeneous groups of anomalies and occupations for exploratory and descriptive purposes limits the value of this type of study. Nevertheless, it provides a good example of the use of a large database to search for teratogenic risk with the aid of malformation registries. ${ }^{35}$

Additional analytical studies are required as well as to the ongoing case-control surveillance programme, to improve evaluation of occupational exposures and identification of specific patterns of defects and prevent occupational risks during pregnancy.

This study was partially supported by the Tuscany Region Administration, Department of Health and Social Safety, Florence, Italy. We are grateful to Dr José F Cordero (Atlanta, USA), Professor Eduardo E Castilla (Rio de Janeiro, Brazil), and Professor Pier Paolo Mastroiacovo (Rome, Italy) for a first revision of the manuscript and Professor Rodolfo Saracci (Lion, France) and Dr Maurizio Clementi (Padua, Italy) for helpful comments.

1 Erickson JD, Cochran WM, Anderson CE. Parental occupation and birth defects. Contributions to Epidemiological Biostatistics 1979;1:107-17.

2 Shaw GM, Gold EP. Methodological considerations in the study of parental occupational exposures and congenital malformations in offspring. Scand $\mathcal{Y}$ Work Environ Health 1988;14:344-55.

3 Hemminki K, Kyrronen P, Lindbohm ML. Spontaneous abortions and malformations in the offspring of nurses exposed to anaesthetic gases, cytostatic drugs, and other potential azars in hospitals, based on registered information of outcome. $\mathcal{f}$ Epidemiol Community Health
1985;39:141-7

4 Tannenbaum TN, Goldberg NJ. Exposure to anesthetic gases and reproductive outcome: a review of the epidemiologic literature. F Occup Med 1985;21:543-8.

5 Kersemaekers WM, Roeleveld N, Zielhuis GA. Reproductive disorders due to chemical exposure among hairdressers. Scand $f$ Work Environ Health 1995;21: 325-34.

6 Clarke M, Mason ES. Leatherwork: a possible hazard to reproduction. $B M \mathcal{F}$ 1985;290:1235-7.

7 McDonald AD, McDonald JC. Outcome of pregnancy in leatherworkers. $B M \mathcal{F}$ 1986;292:979-81.

8 Clarke M, Mason ES. Shoe manufacture and possible hazards to reproduction. $B M \mathcal{F}$ 1988;296:466.

9 Bjerkedal T. Occupation and outcome of pregnancy: a population based study in Norway. In: Moris $M$, ed. Prevention of physical and mental congenital defects, part $b$ : epidemiology, early detection and therapy, and environmental factors. New York: Alan R Liss, 1985:265-8.

10 Holmberg PC, Hernberg S, Kurppa K, Riala R, Rantala K. Oral clefts and organic solvent exposure during pregnancy. Int Arch Occup Environ Health 1982;50:371-6.

11 Kurppa K, Holmberg P, Hernberg S, Rantala K, Riala R, Nurminen T. Screening for occupational exposures and congenital malformation. Preleminary results from a nationwide case-control study. Scand $\mathcal{f}$ Work Environ Health 1983;9:89-93.

12 Cordier S, Ha MC, Ayme S, Goujard J. Maternal exposure and congenital malformations. Scand $\mathcal{f}$ Work Environ Health 1992;18:11-7.

13 Nurminen T, Rantala K, Kurppa K, Holmberg PC. Agricultural work during pregnancy and selected structural malformations in Finland. Epidemiology 1995;6: 23-30.

14 Lechat MF, De Wals P, Weatherall JAC. European Economic Communities concerted action on congenital Economic Communities concerted action on congenital Prevention of physical and mental congenital defects, part $b$ : Prevention of physical and mental congenital defects, part $b$ : epidemiology, early detection and therapy, and environ

15 De Wals P, Mastroiacovo P, Weatherall JAC, Lechat MF. Eurocat guide 1 for the registration of congenital anomalies. Brussels: Department of Epidemiology, Catholic University of Louvain, 1984:1-65.

16 ISTAT. Classificazione delle professioni, serie metodi e norme C/6, Roma: ISTAT, 1981.

17 International Labour Office. International Standard Classification of Occupations ISCO88. Geneva: ILO, 1990.

18 British Paediatric Association. British Paediatric Association classification of diseases. London: BPA, 1979:1-220.

19 Weatherall JAC, De Wals P. EUROCAT guidelines for tabulation of congenital abnormalities and multiple births. Brussels: European Economic Communities, 1981

20 Dean J, Dean A, Burton A, Dicker R. EPI Info version 6.01. Atlanta: Centres for Disease Control and Prevention, 1994.

21 Statistics and Epidemiology Research Corporation, EGRET. Seattle: SEARC, 1993

22 Savitz D, Whelan EA, Rowland AS, Kleckner C. Maternal employment and reproductive risk factors. $A m \mathcal{F}$ Epidemiol 1990;132:933-44.

23 Khoury MJ, Levy MJ, Erickson JD. On the use of affected controls to address recall bias in case-control studies of birth defects. Teratology 1994;49:273-81.

24 Womersley J, Stone H. Epidemiology of facial clefts. Arch Dis Child 1987;62:717

25 Hwang SJ, Beaty TH, Panny SR, Street NA, Joseph JM, Gordon $\mathrm{S}$, et al. Association study of transforming growth factor alpha (TGFa)Taq I polymorphism and oral clefts: indication of a gene-environment interaction in a population-based sample of infants with birth defects. Am 7 Epidemiol 1995;141:629-36.

26 Christensen F, Fogh-Andersen P. Etiological subgroups in non-syndromic isolated cleft palate. A genetic epidemionon-syndromic isolated cleft palate. A genetic epidemiological study of

27 Clementi M, Tenconi R, Collins A, Calzolari E, Milan M Complex segregation analysis in a sample of consecutive newborns with cleft lip with or without cleft palate in Italy. Hum Hered 1995;45:157-64.

28 Regione Toscana. Rischio solventi nel comparto calzaturifici. Un'esperienza nella USL 10/G. Ti con erre sicurezza sociale. Firenze: Regione Toscana, Giunta Regionale, 1991.

29 Scarpelli A, Miligi L, Seniori Costantini A, Alberghini Maltoni S. Exposure to solvents in the shoe and leather goods industries. Int $₹$ Epidemiol 1993;22:S46-50.

30 Holmberg PC, Nurminen M. Congenital defects of CNS and occupational factors during pregnancy: a case-conand occupational factors during pregnan

31 Roeleveld N, Zielhuis GA, Gabreéls F. Occupational exposure and defects of the CNS in offspring: review. $B r \mathcal{F}$ Ind sure and defects of the

32 McDonald JC, Lavoie J, Cote R, McDonald AD. Chemical exposures at work in early pregnancy and congenital defects: a case-control study. $B r \mathcal{F}$ Ind Med 1987;44 527-33.

33 Källèn B. Congenital malformations: infants with more than one malformation diagnosis. Epidemiology of human reproduction. Boca Raton, FL: CRC Press, 1988:31-5.

34 Khoury MJ, Botto L, Waters GD, Mastroiacovo PP, Castilla E, Erickson JD. Monitoring for new multiple congenital anomalies in the search for human teratogens. Am $\mathcal{F}$ Med Genet, 1993;46:460-6.

35 Källèn $B$. Search for teratogenic risk with the aid of malformation registries. Teratology $1987 ; 35: 47-52$. 